\title{
Genetic parameters and efficiency of early selection for half rotation-aged growth and form traits in Pinus taeda in China
}

\author{
By Huixiao YANG ${ }^{1)}$, Tianyi LiU ${ }^{1)}$, ChunXin LiU ${ }^{1)}$, JinBang WANG $^{2)}$, \\ Kaer Chen $^{2)}$, Weihua Zhong ${ }^{1)}$, Bingquan Chen $^{1)}$ and Shaowei Hunang ${ }^{\left.1,3),{ }^{*}\right)}$
}

(Received 25 ${ }^{\text {th }}$ January 2013)

\begin{abstract}
Genetic parameters for height $(\mathrm{H})$, diameter at breast height (DBH), stem straightness (STR), and under crown clear bole height $(\mathrm{CH})$ of loblolly pine (Pinus taeda L.) were estimated for 255 families (209 open pollinated (OP) and 46 controlled pollinated (CP) families) using a family model and an individual tree model at age $1,2,3,5,11$, and 15 years. Heritability estimates for growth traits of individual trees at age 11 years were the highest $(0.17-0.78)$, and those at age 15 years were the lowest $(0.05-0.74)$. Heritability estimates for $\mathrm{DBH}$, STR, and $\mathrm{CH}$ were lower than those for $\mathrm{H}$. Genetic correlations between $\mathrm{H}$ and $\mathrm{DBH}$ were generally strongly positive, attained a maximum values at age 2 to 3 , and declined slightly thereafter. The genetic correlations between $\mathrm{CH}$ at age 11 and both $\mathrm{H}$ and $\mathrm{DBH}$ at different ages were moderate. Age-age genetic correlations for growth traits were moderate to high $(0.56-0.91)$ at age 5 for half-rotation age (15 years), indicating the opportunity exists for early selection. Indirect selection from the age 5 to 11 years for $\mathrm{H}$ and $\mathrm{DBH}$ could be expected to produce gains of over $50 \%$ and $35 \%$ respectively, for these two ages, relative to direct selection at age 15 . Efficiencies of early selection for $\mathrm{H}$ and $\mathrm{DBH}$ indicated that growth at maturity could be improved by early selection.
\end{abstract}

Key words: age-age correlation, genetic correlation, genetic gain, height, heritability, Pinus taeda.

\section{Introduction}

Loblolly pine (Pinus taeda) is the most important commercial tree species in the southern United States because of its good growth characteristics, desirable wood properties, and broad utilization range, with over 1.1 billion seedlings planted annually (McKEAND et al., 2003). The North Carolina State University Cooperative Tree Improvement Program achieved genetic gains up to $30 \%$ using $3^{\text {rd }}$ generation selectively breed loblolly pine when compared with unimproved genetic material (McKEAND et al., 2003). Genetic improvement of loblolly pine was initiated in the 1950 s in several tree improvement programs in the southern USA with the long-term objective of using selective breeding and deployment of

\footnotetext{
1) Guangdong Key Laboratory for Innovative Development and Utilization of Forest Plant Germplasm, South China Agricultural University, College of Forestry, Guangzhou 510642, People's Republic of China.

$\left.{ }^{2}\right)$ Yingde Institute of Forestry, Guangdong 513000, People's Republic of China.

3) State Key Laboratory for Conservation and Utilization of Subtropical Agro-bioresources, Guangzhou 510642, P. R. China.

*) Corresponding author: SHaOwei HuANG. Tel/Fax: 86-2085280259. E-Mail: shwhuang@scau.edu.cn.
}

superior genotypes to improve several traits such as stem volume, tree form, and disease resistance. Some attention has also been paid to wood properties since the 1960s (ZoBEL, 1961). With success in improving tree volume and form traits, the average rotation length for loblolly pine plantations declined to about 25-30 years old (GwAZE et al., 2000, 2001). Loblolly pine is a major non-native plantation species in China and some South American and African countries (GwAZE et al., 2001). Genetic improvement of loblolly pine began in the early 1980s in China; Comprehensive progeny tests and provenance tests were started in the 1990s and some progress has been made in selective breeding (ZHONG et al., 1995).

The selection of elite trees for breeding purposes based on progeny tests was usually conducted before the economic rotation age, because conifer trees typically have long generation intervals. Therefore, testing the age-age correlation of economically important traits is critical to determining the optimal age for early forward selection for breeding purpose and backward selection for establishment of seed orchards (LAMBETH et al., 1983; Wu et al., 2007; KUMAR and LEE, 2002). Many efforts have also been made to evaluate the efficiency of early selection for growth traits (LAMBETH, 1980; MAGNUSSEN, 1988; BURDON, 1989). Several researchers have suggested the most efficient age for selection is between 5 and 10 years based on the growth traits of several conifers (LAMBETH, 1980, 1983; NANSON, 1969; SQUILlaCe and GANSEL, 1974). Age-age genetic correlations have been reported in loblolly pine and were generally very high for younger aged trees compared with trees 15 or 20 years old (LAMBETH et al., 1983; BALOCCHI et al., 1993; GWAZE et al., 1998, 2000; Svensson et al., 1999; LAMBETH and Dill, 2001; Gwaze and Bridgwater, 2002). However, Age-age correlation values were usually low to moderate for older aged trees in the Pinaceae at more than half the rotation age (Wu et al., 2007).

Heritability and age-age genetic correlations for growth and wood density in loblolly pine have also been studied (TALBERT et al., 1983; LOO et al., 1984; ZOBEL and van BuIJTENEN, 1989; WiLliams and MEGRAW, 1994). In a recent report, XIANG et al. (2003) thought that the optimal age for backward selection for height $(\mathrm{H})$ and tree volume on half-sib families was as early as 3 and 4 years of age, respectively. However, a few reports address the genetic parameters and age-age genetic correlation in loblolly pine as a non-native species.

The objectives of this study were: (1) to estimate heritability for growth and form traits at different ages in loblolly pine using a large population (255 families) 
planted in China; (2) to estimate age-age genetic correlation for $\mathrm{H}$ and diameter at breast height (DBH) for different subgroups within the population; and (3) to estimate the efficiency of early selection with half rotationaged loblolly pine.

\section{Materials and Methods}

\section{Genetic material and trial design}

A total of 255 families of loblolly pine were introduced into southern China through the United Nations Development Program (CPR/91/153) from 1992 to 1996, which included 209 open pollinated (OP) and 46 controlled pollinated (CP) families from eight sources in the USA
(Table 1). The eight groups were planted in 1997 on an arenaceous shale lateritic red soil ( $\mathrm{pH}$ 5.2-6.7) in Yingde County, in a subtropical region, western Guangdong Province, China $\left(24^{\circ} 15^{\prime} \mathrm{N}, 113^{\circ} 45^{\prime} \mathrm{E}\right.$, elevation $\left.50 \mathrm{~m}\right)$ in an area with an average annual rainfall of $1,918 \mathrm{~mm}$ and the average slope gradient of less than $25^{\circ}$. To reduce the block size and minimize within-block environmental errors, families were planted into eight adjacent locations and eight original groups of families from different seed sources were established at each location. Each group was planted at only one or two or three test locations. (Fig. 1 and Table 1). Families within each group were planted using $3 \mathrm{~m} \times 3 \mathrm{~m}$ spacing, with six or seven replications, and using a randomized complete

Table 1. - Designation of eight loblolly pine family groups, their test locations, and sources and trait means \pm standard error for height $(\mathrm{H})$ and diameter at breast height $(\mathrm{DBH})$ at age 11 years.

\begin{tabular}{cccccllc}
\hline Group & No of Families & Location & Rep & Trees/Plol & Source & H11 & DBHJI \\
\hline G1 & 25 & $11 / 12$ & 6 & 6 & OP plus trees & $6.06 \pm 1.65 \mathrm{~d}$ & $8.28 \pm 2.35 \mathrm{a}$ \\
G2 & 33 & $5 / 6$ & 6 & 6 & OP plus trees & $5.61 \pm 1.04 \mathrm{e}$ & $7.01 \pm 2.05 \mathrm{~d}$ \\
G3 & 24 & $3 / 7$ & 6 & 6 & OP second-generation seed orchard & $6.70 \pm 0.94 \mathrm{bc}$ & $7.29 \pm 2.30 \mathrm{c}$ \\
G4 & 29 & $4 / 8 / 9$ & 6 & 6 & OP first-generation seed orchard & $7.20 \pm 1.20 \mathrm{a}$ & $7.69 \pm 2.36 \mathrm{~b}$ \\
G5 & 44 & $10 / 11$ & 6 & 5 & OP first-generation seed orchard & $6.50 \pm 1.01 \mathrm{c}$ & $7.27 \pm 2.37 \mathrm{c}$ \\
G6 & 29 & $2 / 4$ & 6 & 6 & OP first-generation seed orchard & $5.92 \pm 1.07 \mathrm{~d}$ & $7.33 \pm 2.49 \mathrm{c}$ \\
G7 & 25 & $9 / 10$ & 6 & 5 & OP first-generation seed orchard & $6.75 \pm 1.58 \mathrm{~b}$ & $8.23 \pm 2.58 \mathrm{~d}$ \\
G8 & 46 & 8 & 7 & 5 & CP selection first-generation seed orchard & $7.10 \pm 1.02 \mathrm{a}$ & $7.19 \pm 2.24 \mathrm{c}$ \\
Total & 25.5 & & - & - & & & \\
\hline
\end{tabular}

Values within a column followed by the same letter are not significantly different from $\alpha=0.05$ using Duncan's test (R package "Agricolae").

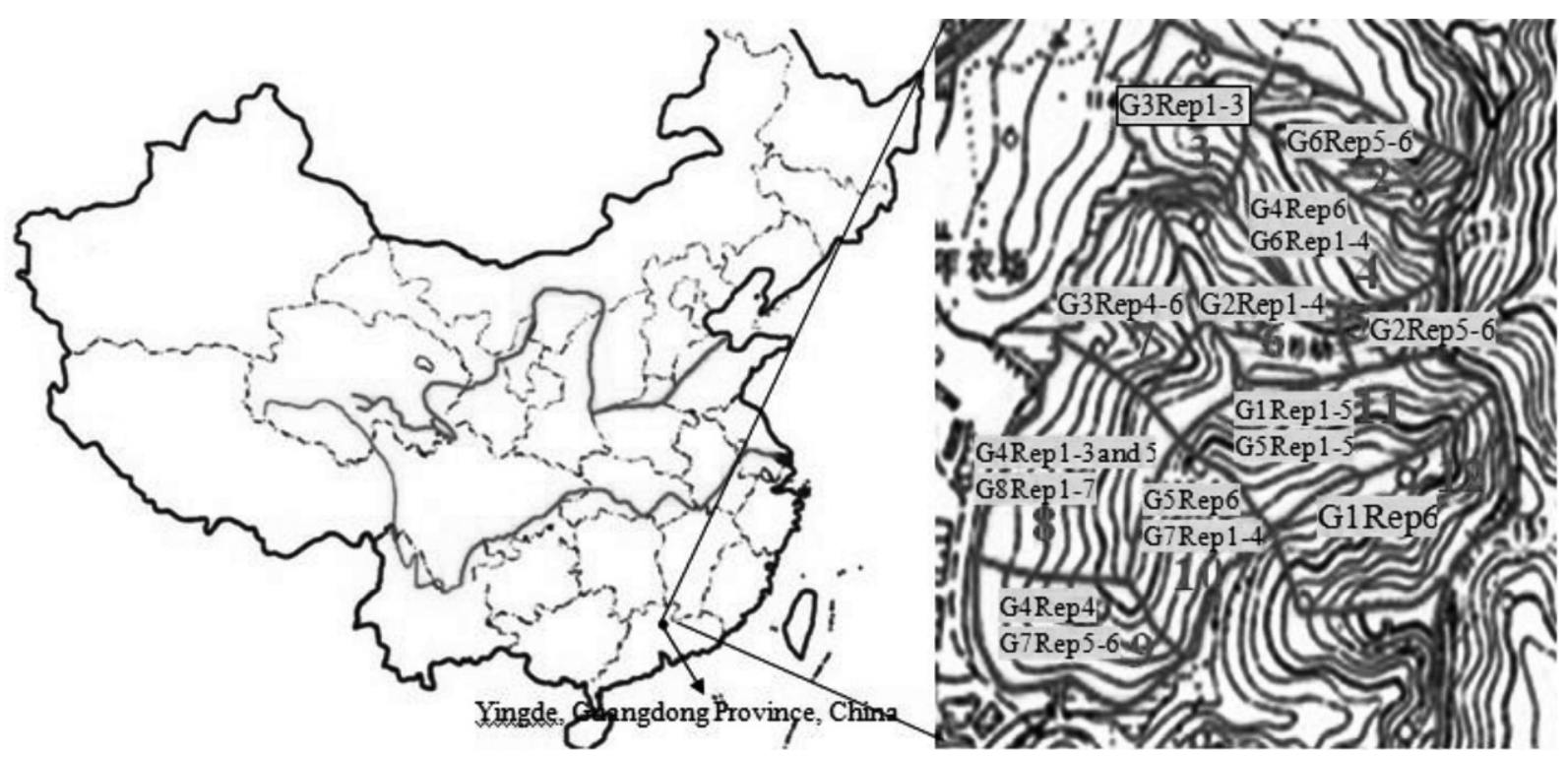

Figure 1. - Location of progeny trials of eight loblolly pine groups in Yingde Institute of Forestry in china. The read lines indicate the road. G indicates group number, Rep indicates replication number. Location 2 has G6Rep5-6, Location 3 has G3Rep1-3, Location 4 has G4Rep6 and G6Rep1-4, Location 5 has G2Rep5-6, Location 6 has G2Rep1-4, Location 7 has G3Rep4-6, Location 8 has G4Rep1-3and 5 and G8Rep1-7, Location 9 has G4Rep4 and G7Rep5-6, Location 10 has G5Rep6 and G7Rep1-4, Location 11 has G1Rep1-5 and G5Rep1-5, Location12 has G1Rep6. 
block design for each group of families with 5- or 6-trees per row in each plot.

Measures of $\mathrm{H}$ and $\mathrm{DBH}$ were made during 1997, 1998, 1999, 2001, 2007, and 2011 for all families of the eight groups. $\mathrm{DBH}$ was measured at $1.3 \mathrm{~m}$ above the ground. Stem straightness (STR) and under crown clear bole height $(\mathrm{CH})$ was measured at age 11 years, and STR was scored on a scale of 1 (most crooked) to 5 (straightest).

\section{Statistical analysis}

Summary statistics were computed using $\mathrm{R}$ software ( $\mathrm{R}$ Version 2.15.1, $\mathrm{R}$ Development Core Team, 2012) and statistical analyses were conducted on all eight groups using ASReml 3.0 software (GILMOUR et al., 2004). First, $\mathrm{H}$ and $\mathrm{DBH}$ measurements at different ages were analyzed as a single trait. Each trait from the eight groups (univariate, single-group) was analyzed to estimate individual-tree narrow heritability and standard errors. Likelihood ratio testing was used to identify non-significant non-genetic effects which would be removed and then used to identify the best model for the eight groups as well as for the combined data. A family linear mixed model was used for open pollinated family with location and the interaction of location and replication as fixed effects, and family as random effects:

$$
Y_{i j k l}=\mu+L_{i}+R\left(L_{i j}\right)+F_{k}+e_{(i j k) l}
$$

where $Y_{i j k l}$ was the observation of the $l^{\text {th }}$ tree from the $k^{\text {th }}$ family in the $j^{\text {th }}$ replication within the $i^{\text {th }}$ location, $\mu$ was the overall mean, $L_{i}$ was the fixed effect of the $i^{\text {th }}$ location, $R\left(L_{i j}\right)$ was the fixed effect of $j^{\text {th }}$ replication within the $i^{\text {th }}$ location, $F_{k}$ was the random effect of family $\mathrm{N}\left(0, \sigma_{F}^{2}\right)$, and $e_{(i j k) l}$ was the random residual effect $\mathrm{N}\left(0, \sigma_{E}^{2}\right)$.

Another linear mixed effects model was used for control pollinated families with location and replication within location as fixed effects, and parental effects as random effects. Parental interaction was considered because the mating design was irregular and imbalanced.

$$
Y_{i j k l m}=\mu+L_{i}+R\left(L_{i j}\right)+F_{k}+M_{l}+e_{(i j k l) m}
$$

where $Y_{i j k l m}$ is the individual tree measurement, $\mu, L_{i}$, and $R\left(L_{i j}\right)$ were defined above, $F_{k}$ and $M_{l}$ are the random effect of female $\mathrm{N}\left(0, \sigma_{f}^{2}\right)$ and male $\mathrm{N}\left(0, \sigma^{2}{ }_{m}\right)$, and e is the random residual effect $\mathrm{N}\left(0, \sigma_{E}^{2}\right)$.

Univariate and pedigree (e.g. combined open pollinated families) analysis was also conducted to estimate individual-tree narrow sense heritability for all families and the additive genetic correlations between traits using an individual tree mixed linear model. Approximate standard errors of statistics were obtained by Taylor expansion within the ASReml programme. Onetailed likelihood ration test (LRT) was applied to assess the statistical significance of additive variances (STRAM and LEE, 1994).

$$
\begin{array}{r}
Y_{i j k l m n}=\mu+L_{i}+R\left(L_{i j}\right)+G_{k}+T_{i j k l}+ \\
L_{i} \cdot G_{k}+L \cdot F_{m}(G)_{i k m}+e_{(i j k l m) n}
\end{array}
$$

where $Y_{i j k l m n}$ is the individual tree measurement, $\mu, L_{i}$, and $R\left(L_{i j}\right)$ were defined above, and $G_{k}$ was the fixed effect of group $\mathrm{N}\left(0, \sigma^{2}{ }_{k}\right), T_{i j k l}$ was the additive genetic effect of individual tree $\mathrm{N}\left(0, \sigma^{2}{ }_{T}\right), L_{i} \cdot G_{k}$ and $L . F_{m}(G)_{i k m}$ were the random effect of groups by location interaction and family within groups by location $\mathrm{N}\left(0, \sigma_{L . F}^{2}\right)$, respectively, and $e_{(i j k l m) n}$ was the random residual $\mathrm{N}\left(0, \sigma_{E}^{2}\right)$. The starting values for the joint analyses were obtained from single group analyses.

Observed variance components were used to estimate the causal variance component and individual-tree narrow sense heritability for each trait: $\sigma^{2}{ }_{A}=$ estimate of additive genetic variance (e.g. $\sigma_{A}^{2}=4 \sigma_{F}^{2}$ for OP families, $\sigma_{A}^{2}=2 \sigma_{f}^{2}+2 \sigma_{m}^{2}$ for CP families, $\sigma_{A}^{2}=\sigma_{T}^{2}$ for combined data); $\sigma_{P}^{2}=$ estimate of phenotypic variance $\left(\sigma_{P}^{2}=\sigma_{F}^{2}+\sigma_{E}^{2}\right.$ for OP families, $\sigma_{P}^{2}=\sigma_{f}^{2}+\sigma_{m}^{2}+\sigma_{F}^{2}$ for CP families, $\sigma_{P}^{2}=\sigma_{F(G)}^{2}+\sigma_{T}^{2}+\sigma_{E}^{2}$ for combine data), and

$$
h_{i}^{2}=\frac{\sigma_{A}^{2}}{\sigma_{P}^{2}}
$$

estimate of individual-tree narrow-sense heritability. The coefficients of relationship for OP families and combined data of one-fourth and one-half of all CP families were assumed since data from molecular genetic studies of the 1978 natural population collection indicated very low levels of selfing or inbreeding (MoRAN et al., 1988; VoGL et al., 2002) Multivariate, multi-location (all traits and $\mathrm{OP}$ and $\mathrm{CP}$ families ) analysis was conducted to estimate additive genetic correlations between traits across 11 locations using a model similar to equation (3), except that here $L_{i} . G_{k}$ and $L . F_{l}(G)_{i k l}$ were not included in this model.

Early- to half rotation-age and trait and trait genetic correlations were calculated as:

$$
r=\frac{\operatorname{cov}_{f E H}}{\sqrt{\sigma_{f E}^{2} \times \sigma_{f H}^{2}}}
$$

where $c o v_{f E H}$ is the family covariance among early age $E$ and later age $H$ (e.g. $H=15$ for half rotation) for each group or combined data, $\sigma_{f E}^{2}$ and $\sigma^{2}{ }_{f H}$ are family variances for early age $E$ (at age $1,2,3,5$ and 11 years) and half rotation age $H$ (at age 15 years), respectively. The additive genetic correlations between traits were computed using similar to equation (4). Statistical significance for heritability and genetic correlations was tested using standard errors of the estimates and normal distribution probability.

The efficiency of early selection relative to half rotation age (at age 15 years) per generation is calculated as

$$
E_{g e n}=\frac{i_{j} r_{A} h_{j}}{i_{m} h_{m}}
$$

where $i_{j}$ and $i_{m}$ are the selection intensity at the juvenile at age $1,2,3,5,11$ and mature at age 15 years, $h_{j}$ and $h_{m}$ are the square root of the heritability at the juvenile and mature age, respectively, and $r_{A}$ is the additive genetic correlation between the juvenile and half rotation age. The same selection intensity for the juvenile and mature traits was used in this formula.

The genetic gain efficiency of early selection per year was also calculated as follows (LAMBETH, 1980): 


$$
E_{y e a r}=\frac{i_{j} r_{A} h_{j}\left(T_{m}+d\right)}{i_{m} h_{m}\left(T_{j}+d\right)}
$$

where $T_{m}$ and $T_{j}$ are the ages 15 and juvenile selection, and $d$ is the interval time between selection and establishment of the new progeny test. The interval $d$ was assumed to be 5 years, comprising 2 years for grafting, 2 years for pollination and seed maturation, and 1 year for growing seedlings in the nursery (LI and WU, 2005).

\section{Results and Discussion}

\section{Trends with age for heights and $\mathrm{DBH}$}

Significant differences in $\mathrm{H}$ and $\mathrm{DBH}$ at age 11 years were observed among the eight groups (Table 1). The overall trends of $\mathrm{H}$ and $\mathrm{DBH}$ growth in each group followed an s-shaped curve of slow-fast-slow growth (Fig. 2). For both $\mathrm{H}$ and $\mathrm{DBH}$, the growth for the first three years was relatively slow, probably because of the need for a root recovery period. The $\mathrm{H}$ and $\mathrm{DBH}$ entered a fast-growing period from ages 3 to 11 years. The average value of $\mathrm{H}$ at age 5 reached $4.1 \mathrm{~m}$ and increased to $7.7 \mathrm{~m}$ at age 11. The $\mathrm{DBH}$ changed from $6.6 \mathrm{~cm}$ at age 5 years to $12.9 \mathrm{~cm}$ at age 11 . Families 86 and 81 belonged to a G8 group that had consistently larger $\mathrm{Hs}$ and $\mathrm{DBHs}$ than the other groups at age 15 years; this consistent growth indicated that selection between families at an early age would be effective. GwAZE et al. (2002) reported height-age relationships in tests of younger trees were essentially linear but the relationship of the older test trees was non-linear for loblolly pine.

\section{Age trends of additive variance and heritability} for height and $D B H$

The additive variances for $\mathrm{H}$ and $\mathrm{DBH}$ were low $(0.07-0.24$, and $0.02-0.85)$ at age $2,3,5$ years, and then increased to 0.75 and 2.51 at age 11 , and finally declined to 0.62 and 2.04 at age 15 years for combined groups (Table 2), respectively. The percentage of additive variance for $\mathrm{H}$ and $\mathrm{DBH}$ were the largest at age 11 (Fig. 3). The age trend for additive genetic variance in tree $\mathrm{H}$ and DBH observed in this study were similar to that reported by FRANKLIN (1979). FRANKLIN observed that the additive variance of loblolly pine for $\mathrm{H}$ remained very low until the time of stand closure (at age 3 to 5 ), then increased rapidly from age 6 to 20 years, and finally additive variance declined from age 20 to 25 years old.

We estimated heritability as the ratio of additive to total genetic variance for combined groups for each trait. The age-trends of heritability estimates for $\mathrm{DBH}$ were non-linear, peaking at 11 years (Table 3). The estimated heritabilities were relatively higher than most estimates for tree $\mathrm{H}$ and $\mathrm{DBH}$, which might indicate a relationship exists among families within groups and between groups that was not accounted for in the analyses. Balocchi et al. (1993) found narrow-sense heritabilities for loblolly pine were near zero at 8 years, and then they increased sharply up to age 16 years and declined at the final measurement at age 26. The trends for narrowsense heritabilities in the present study are consistent with those reported by FRANKLIN (1979), in which heritability of $\mathrm{H}$ was increasing between ages 10 and 20 years, and finally declined to its lowest level at age 25 years old. The tendency of high individual-tree heritabilities for $\mathrm{H}$ and $\mathrm{DBH}$ for young loblolly pine (2-11) implies that the expected gain would be higher if selection was applied at these young ages, particularly from seedling progeny trials. Higher heritabilities for $\mathrm{H}$ relative to diameter have been reported in other studies which indicate that genetic expression in $\mathrm{H}$ is not affected much by environmental variation (NANCE and
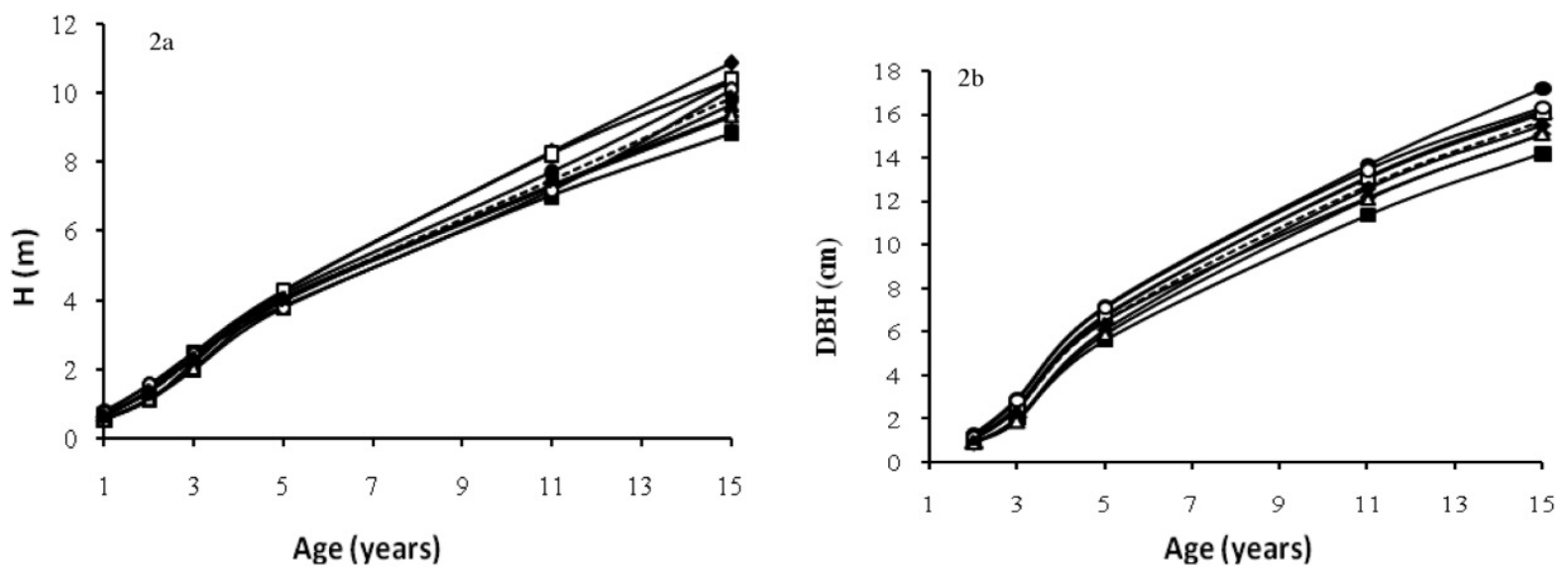

Figure 2. - Age trends for height growth (2a) and DBH growth (2b) in 8 groups and combined groups, each group is represented by different legends.

Table 2. - Analysis of variance components for the effects of trees $\left(\mathrm{V}_{\mathrm{T}}\right)$ and residual errors $\left(\mathrm{V}_{\mathrm{E}}\right)$ for height and $\mathrm{DBH}$ (diameter at breast height) for ages $2,3,5,11$, and 15 years.

\begin{tabular}{lllllllllll}
\hline age & $\mathrm{H} 2$ & $\mathrm{H} 3$ & $\mathrm{H} 5$ & $\mathrm{H} 11$ & $\mathrm{~h} 15$ & $\mathrm{DBH} 2$ & $\mathrm{DBH} 3$ & $\mathrm{DBH} 5$ & $\mathrm{DBH} 11$ & $\mathrm{DBH} 15$ \\
\hline $\mathrm{V}_{\mathrm{T}}$ & $0.072^{* * *}$ & $0.143^{* * *}$ & $0.240^{* * *}$ & $0.747^{* * *}$ & $0.624^{* * *}$ & $0.022^{* * *}$ & $0.262^{* * *}$ & $0.854^{* * *}$ & $2.513^{* * *}$ & $2.036^{* * *}$ \\
$\mathrm{~V}_{\mathrm{E}}$ & 0.052 & 0.117 & 0.218 & 0.601 & 2.244 & 0.157 & 0.577 & 1.490 & 3.514 & 7.357 \\
\hline
\end{tabular}

Note: *,***** indicate significance for $P \leq 0.05, P \leq 0.01, P \leq 0.001$, respectively. 


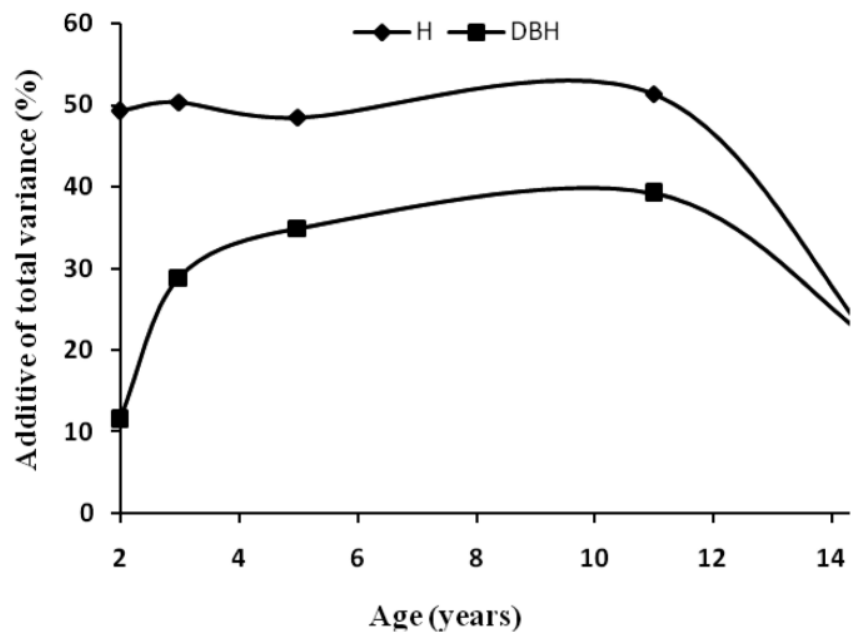

Figure 3. - The ratio of additive to total genetic variance over time for $\mathrm{H}$ and $\mathrm{DBH}$.

WelLes, 1981; Foster and BRIDGWATER, 1986; BALOCCHI et al., 1993).

\section{Age trends of heritability in different groups}

In this paper, significant heritability was also observed for all traits and for all groups with a few of exceptions; heritability for observed $\mathrm{H}$ and $\mathrm{DBH}$ was high regardless of groups and ages. For example, for $\mathrm{H}$ at 5 years-old, all groups had significant heritability estimates except for three groups (G6, G1 and G3). Heritability for $\mathrm{H}$ at different ages ranged from 0.04 to 0.88 with a mean heritability 0.38 , while heritability for DBH at different ages ranged from 0.01 to 0.49 with a mean heritability 0.26 . Heritability for $\mathrm{H}$ for different groups attained to the maximum value with a mean 0.36 at 11 years, and thereafter dropped quickly at 15 years. Similarly, heritability of DBH for different groups reached about 0.32 at age 11 , then fell after that age. These results may suggest the heritability decreases with increased competition. The heritability of $\mathrm{H}$ for G8 group at different ages changed from 0.16 to 0.45 , which is comparable to or slightly higher than results obtained in previous studies using full-sib families (ERICSSON and Fries, 2004; Fries and ERICSSON, 2006, 2009; Fries, 2012). GWAZE et al. (2001) reported 0.04 to 0.61 individ- ual-tree heritabilities for DBH for loblolly pine at two sites in the West Gulf Coastal Plain of the United States at 5 -year intervals from 5 to 25 years. IsIK et al. (2004) also reported 0.05 and 0.03 individual-tree heritabilities for within half-sib families and full-sib families for loblolly pine from seedling data at 6 years, respectively. Heritability for STR and $\mathrm{CH}$ at age 11 was very low for different groups, with mean heritability at 0.21 and 0.12 , respectively. The heritability for STR and $\mathrm{CH}$ were lower than those of other reports (SHELbourne, 1996; Shelbourne et al., 1967; WoEsSner, 1965; NikLES, 1966; WiLLIAMS and LAMBETH, 1989).

\section{Genetic correlation between height and DBH and form traits}

The genetic correlations between $\mathrm{H}$ and $\mathrm{DBH}$ were moderate to high (0.49-0.98) except for the correlation between $\mathrm{H} 2$ and DBH15 (Table 4). The correlation between $\mathrm{H}$ and DBH had the highest value at age 2 and 3 years and then declined slightly thereafter. The results, therefore, show that early $\mathrm{H}$ selection may not always be a good predictor of diameter at half rotation age. There were generally low genetic correlations between $\mathrm{H}$ and DBH with STR (0.01-0.42), and genetic correlations between $\mathrm{H}$ and $\mathrm{CH}$ varied from 0.48 at age 1 to 0.69 at 5 years, and decreased slowly to 0.53 at 15 years (Table 4). For the correlation between DBH and $\mathrm{CH}$, the correlation coefficient reached a maximum of 0.60 at 3 years, and then decreased slowly to 0.47 at 15 years (Table 4). Positively correlated genetic traits imply that selection for one trait should also lead to improvement in the second trait; in the case of $\mathrm{H}, \mathrm{DBH}, \mathrm{CH}$, and STR, positive genetic correlations for one trait can lead to gains for that trait based on selection for another trait.

\section{Age to age genetic correlation}

The additive genetic correlations between half rotation age and earlier ages are presented for different family groups and the combined family group (Fig. 4). The genetic correlation for $\mathrm{H}$ for G7, G1, G3 and G8 reached a much higher value $(>0.8)$ at 3 years (Fig. $4 a)$ while other populations reached between 0.5 and 0.8 at 5 years. The genetic correlation of all groups for $\mathrm{H}$ increased to above 0.8 at age 11 years. Similar to $\mathrm{H}$, age

Table 3. - Heritability estimates \pm standard error for different height, diameter at breast height, stem straightness, and under crown clear bole height for eight loblolly pine progeny groups in China. Statistical significance is indicated by: ${ }^{1} P<0.10 ;{ }^{2} P<0.05$; ${ }^{3} P<0.01 ;{ }^{4} P<0.001 ;{ }^{\text {ns }}$ non-significant.

\begin{tabular}{|c|c|c|c|c|c|c|c|c|c|c|c|c|c|}
\hline $\mathrm{h}^{2}$ & $\mathrm{HI}$ & $\mathrm{H} 2$ & $\mathrm{H} 3$ & H5 & HII & HI5 & DBH2 & DBH 3 & DBH 5 & DBH 11 & DBH 15 & STR11 & CHII \\
\hline G) & $37 \pm 0.16^{2}$ & $2.5 \pm 0.14^{2}$ & $40 \pm 0.18^{3}$ & $0.35 \pm 0.15^{2}$ & $28 \pm 0.14^{2}$ & $0.40 \pm 0.16^{5}$ & $13 \pm 0.15^{n *}$ & $0.31 \pm 0.15^{2}$ & $0.26 \pm 0.13^{2}$ & $0.32 \pm 0.14^{2}$ & $0.28 \pm 0.13^{2}$ & $0.23 \pm 0.11^{2}$ & $0.31 \pm 0.13^{2}$ \\
\hline $\mathrm{G} 2$ & $0 \pm 0.14^{3}$ & $30 \pm 0.12^{3}$ & $23 \pm 0.10^{2}$ & $0.37 \pm 0.13^{3}$ & $27 \pm 0.11^{3}$ & $0.05 \pm 0.07^{113}$ & $01 \pm 0.07^{\mathrm{ths}}$ & $0.19 \pm 0.10^{2}$ & $0.17 \pm 0.10^{2}$ & $0.17 \pm 0.09^{\underline{2}}$ & $0.03 \pm 0.07^{\mathrm{nix}}$ & $0.06 \pm 0.07^{\mathrm{es}}$ & $0.01 \pm 0.07^{\mathrm{r}}$ \\
\hline G3 & $8 \pm 0.14^{2}$ & $.23 \pm 0.13^{2}$ & $.14 \pm 0.10^{\prime}$ & $0.11 \pm 0.08^{n s}$ & $26 \pm 0.1]^{3}$ & $0.15 \pm 0.08^{2}$ & $10 \pm 0.12^{\mathrm{ni}}$ & $0.09 \pm 0.09^{1 \mathrm{~h}}$ & $0.18 \pm 0.10^{2}$ & $0.21 \pm 0.10^{2}$ & $0.10 \pm 0.08^{\prime}$ & $0.09 \pm 0.07^{r . . k}$ & $0.06 \pm 0.07^{r .}$ \\
\hline G4 & - & $0.65 \pm 0.16^{4}$ & $0.58 \pm 0.14^{4}$ & $0.51 \pm 0.14^{2}$ & $0.43 \pm 0.12^{4}$ & $0.18 \pm 1.09^{2}$ & $0.02 \pm 0.09^{1 \mathrm{kx}}$ & $0.48 \pm 0.14^{2}$ & $0.48 \pm 0.14^{4}$ & $0.64 \pm 0.15^{4}$ & $0.49 \pm 0.13^{4}$ & $0.13 \pm 0.07^{2}$ & 108 \\
\hline G5 & $36 \pm 0.17^{+}$ & $0.41 \pm 0.16^{3}$ & $0.35 \pm 0.13^{3}$ & $0.21 \pm 0.10^{+}$ & $0.21 \pm 0.10^{2}$ & $0.25 \pm 0.12^{2}$ & $0.01 \pm 0.16^{\mathrm{ns}}$ & $0.56 \pm 0.17^{i}$ & $0.42 \pm 0.14^{3}$ & $0.34 \pm 0.12^{3}$ & $0.31 \pm 0.12^{3}$ & $0.11 \pm 0.07^{1}$ & $0.22 \pm 0.10^{2}$ \\
\hline G6 & $88 \pm 1.25^{6}$ & $.74 \pm 0.24^{3}$ & $0.57 \pm 0.200^{5}$ & $0.69 \pm\left(0.21^{\text {ni }}\right.$ & $0.78 \pm 0.23^{4}$ & $0.74 \pm\left(1.22^{4}\right.$ & $0.02 \pm 0.19^{\text {lix }}$ & $0.45 \pm 0.18^{7}$ & $0.36 \pm 0.15^{3}$ & $0.35 \pm 0.13^{3}$ & $0.25 \pm 0.12^{2}$ & $0.02 \pm 0.04^{1-x}$ & 0.17 \\
\hline 67 & $.88 \pm 0.24^{+}$ & $.46 \pm 0.19^{3}$ & $0.09 \pm 0.12^{r . x}$ & $0.04 \pm 0.09^{\mathrm{ne}}$ & $0.17 \pm 0.10^{1}$ & $0.11 \pm 0.08^{1}$ & $0.38 \pm 0.19^{2}$ & $0.26 \pm 0.15^{2}$ & $0.28 \pm 0.14^{2}$ & $0.21 \pm 0.11^{2}$ & $0.13 \pm 0.10^{1}$ & $0.16 \pm 0.08^{2}$ & $0.04 \pm 0.09^{\mathrm{r}}$ \\
\hline G8 & $16 \pm 005^{3}$ & $0.18 \pm 0.06^{3}$ & $0.26 \pm 0.077^{4}$ & $0.38 \pm 0.10^{4}$ & $0.45 \pm 0.100^{4}$ & $0.39 \pm\left(1.09^{6}\right.$ & $106^{3}$ & $0.19 \pm 0.06^{\circ}$ & $0.21 \pm 0.06$ & $0.36 \pm$ & & $0.09 \pm 0.04^{1}$ & $0.06 \pm 0.04$ \\
\hline mbined & $38 \pm 0.04^{4}$ & $0.52 \pm 0.05^{4}$ & $0.50 \pm 0.05^{+}$ & $0.48 \pm 0.05^{-4}$ & $0.51 \pm 0.05^{4}$ & $0.18 \pm 0.02^{4}$ & $0.11 \pm 0.0 .3^{+}$ & $0.28 \pm 0.03^{-}$ & $0.34 \pm 0.04^{4}$ & $0.39 \pm 0.04^{4}$ & $0.19 \pm 0.03^{4}$ & $0.07 \pm 0.01^{7}$ & $0.20 \pm 0.03^{+}$ \\
\hline
\end{tabular}

$\mathrm{H}$ (height), DBH (diameter at breast height) at age 1, 2, 3, 5, 11, 15 years, stem straightness (STR11), and under crown clear bole height (CH11) at age 11years. 
Table 4. - Genetic correlation estimates \pm standard error for different traits for loblolly pine progeny in China. Statistical significance is indicated by: ${ }^{1} P<.10 ;{ }^{2} P<.05 ;{ }^{3} P<.01 ;{ }^{4} P<.001 ;$ ns non-significant.

\begin{tabular}{lllllllll}
\hline & $\mathrm{H} 1$ & $\mathrm{H} 2$ & $\mathrm{H} 3$ & $\mathrm{H} 5$ & $\mathrm{H} 11$ & $\mathrm{H} 15$ & STR11 & $\mathrm{CH} 1 \mathrm{I}$ \\
\hline DBH2 & $.87 \pm .05^{4}$ & $0.98 \pm 0.01^{4}$ & $0.87 \pm 0.03^{4}$ & $0.74 \pm 0.06^{4}$ & $0.53 \pm 0.09^{4}$ & $0.28 \pm 0.11^{4}$ & $0.20 \pm 0.13^{2}$ & $0.33 \pm 0.11^{3}$ \\
DBH3 & $0.82 \pm 0.04^{4}$ & $0.95 \pm 0.01^{4}$ & $0.95 \pm 0.01^{4}$ & $0.87 \pm 0.02^{4}$ & $0.67 \pm 0.05^{4}$ & $0.49 \pm 0.07^{4}$ & $0.06 \pm 0.10^{\mathrm{ns}}$ & $0.60 \pm 0.07^{4}$ \\
DBH5 & $0.71 \pm 0.05^{4}$ & $0.88 \pm 0.02^{4}$ & $0.90 \pm 0.02^{4}$ & $0.87 \pm 0.02^{4}$ & $0.73 \pm 0.04^{4}$ & $0.62 \pm 0.06^{4}$ & $0.03 \pm 0.10^{\mathrm{ns}}$ & $0.59 \pm 0.07^{4}$ \\
DBH 11 & $0.54 \pm 0.06^{4}$ & $0.73 \pm 0.04^{4}$ & $0.78 \pm 0.03^{4}$ & $0.80 \pm 0.03^{4}$ & $0.76 \pm 0.03^{4}$ & $0.73 \pm 0.04^{4}$ & $0.01 \pm 0.10^{\text {ns }}$ & $0.48 \pm 0.08^{4}$ \\
DBH 15 & $0.49 \pm 0.07^{4}$ & $0.62 \pm 0.06^{4}$ & $0.69 \pm 0.05^{4}$ & $0.75 \pm 0.04^{4}$ & $0.76 \pm 0.04^{4}$ & $0.76 \pm 0.04^{4}$ & $0.09 \pm 0.11^{115}$ & $0.47 \pm 0.09^{4}$ \\
STR11 & $0.09 \pm 0.09^{\mathrm{n}}$ & $0.04 \pm 0.10^{\mathrm{ns}}$ & $0.09 \pm 0.10^{\mathrm{ns}}$ & $0.17 \pm 0.10^{2}$ & $0.42 \pm 0.09^{4}$ & $0.29 \pm 0.10^{3}$ & - & $0.18 \pm 0.11^{2}$ \\
CH11 & $0.48 \pm 0.07^{4}$ & $0.54 \pm 0.07^{4}$ & $0.66 \pm 0.06^{4}$ & $0.69 \pm 0.06^{4}$ & $0.66 \pm 0.06^{4}$ & $0.53 \pm 0.08^{4}$ & $0.18 \pm 0.11^{\text {ns }}$ & - \\
\hline
\end{tabular}

$\mathrm{H}$ (height), DBH (diameter at breast height) at age 1, 2, 3, 5, 11, 15 years, stem straightness (STR11), and under crown clear bole height (CH11) at age 11years.

to age genetic correlation estimates for $\mathrm{DBH}$ increased to 0.80 at 5 years except for group G4 and G5, and additive genetic correlation estimates increased to 0.80 at age 11 years for all groups (Fig. $4 b$ ). The results indicated that indirect selection at age 5 was $80 \%$ as effective as selection at age 15, and selection at age 3 was $70 \%$ as effective as selection at age 15 .

Age-age genetic correlations for $\mathrm{H}$ generally agreed with previously estimates published for loblolly pine (Foster, 1986; LAMBETH et al., 1983; GWAZE et al., 2000; GwAZEL and BrIDGwATER, 2002). However, SvEnsson et al. (1999) reported the genetic correlations of juvenile $\mathrm{Hs}$ with $\mathrm{H}$ at age 11 were generally high and stable for all ages (>0.97) in loblolly pine open-pollinated families during canopy closure. DANJON (1994) reported the

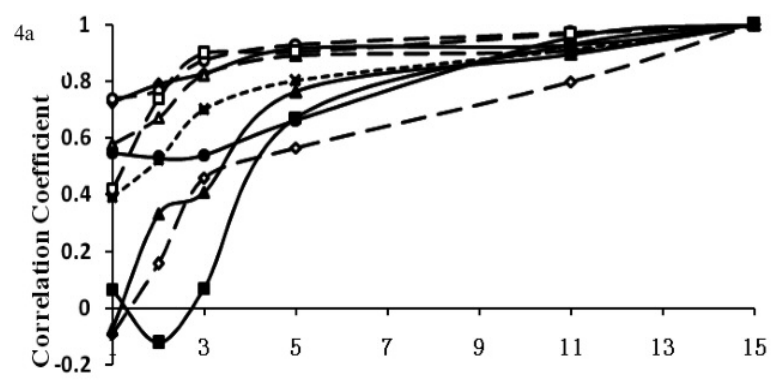

Age (years)

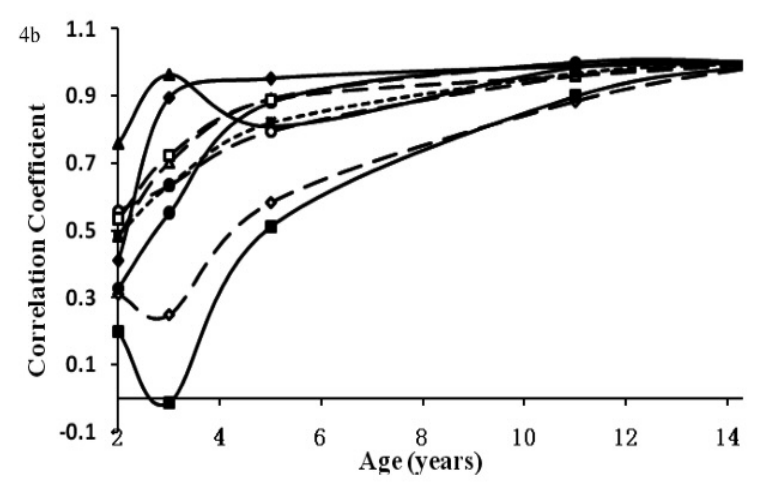

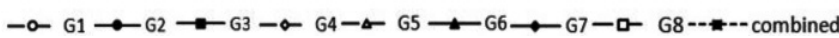

Figure 4. - Genetic correlations between earlier ages and age 15 years to $\mathrm{H}(4 \mathrm{a})$ and $\mathrm{DBH}(4 \mathrm{~b})$ for different groups and the combined groups. genetic correlations between early $\mathrm{Hs}$ and $\mathrm{Hs}$ at rotation age were null or negative (from -0.11 to 0.06 ) in maritime pine.

\section{Efficiency of early selection relative to selection at half-rotation age}

Early selection was more efficient for $\mathrm{H}$ than $\mathrm{DBH}$ with selection of the best $15 \%$ of all individuals (Fig. 5). This mainly was caused by the higher heritability for $\mathrm{H}$ at early ages. Efficiency for $\mathrm{H}$ was greater than 1 (100\%) at 2 years while the same efficiency was achieved at age 5 for $\mathrm{DBH}$. The optimal selection age for $\mathrm{H}$ and $\mathrm{DBH}$ was estimated to be at age 9-11 years for individual (forward) selection, which is consistent with the literature (LAmbeth, 1980; Squillace and Gansel, 1974). Early selections for $\mathrm{H}$ at age 2 years and for DBH at age 5 years were equally efficient as selection at half rotation age (Fig. 5). The most effective years for early selection, based on gain achieved per year, are between ages 2 and 5 years for $\mathrm{H}$, and between ages 3 and 5 years for DBH, based on these data (Fig. 6). This efficiency has a more practical utility in a breeding program. This indicates that breeders don't have to wait for formulation of mature wood (usually around age 15 years) for the selection of breeding material.

It was difficult to make comparisons with other studies for early selection since the measurements used to make correlations with mature age trees in those stud-

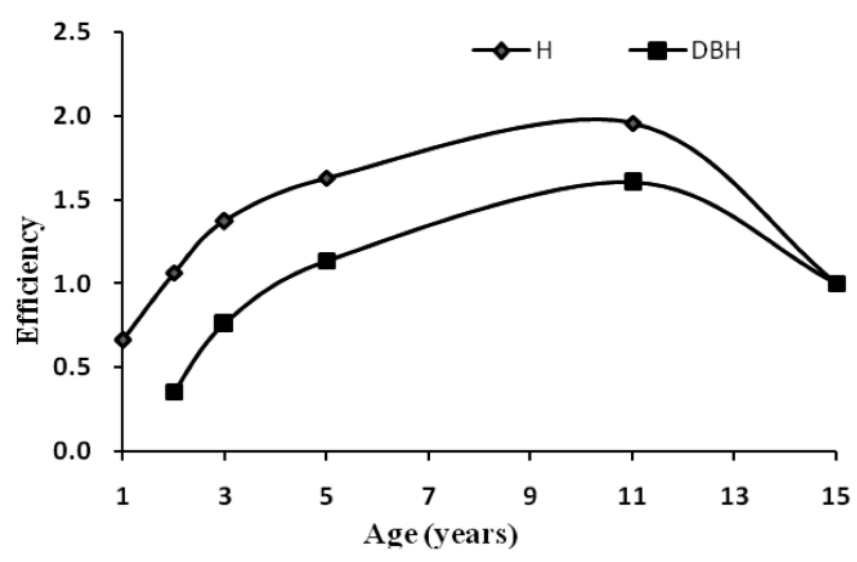

Figure 5. - Efficiency of early individual selection relative to selection at age 15 for height $(\mathrm{H})$ and diameter at breast height $(\mathrm{DBH})$. 


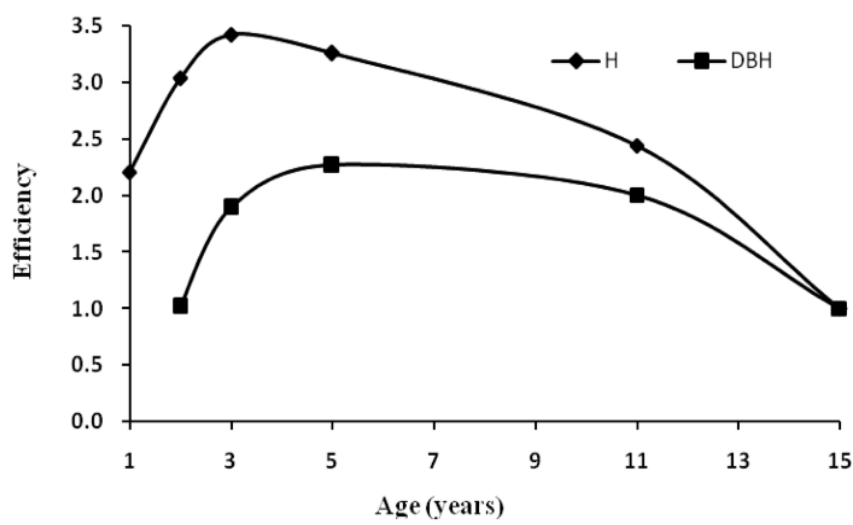

Figure 6. - Efficiency of early individual selection in terms of gain per year for height $(\mathrm{H})$ and diameter at breast height (DBH).

ies varied widely; for example, gains were computed based on gain per generation or gain per year in different studies. Early selection efficiency for $\mathrm{H}$ and $\mathrm{DBH}$ should be considered with caution because of the small sample size. FOSTER (1986) found families selected for total plot volume at age 15 years should be as early as age 3 years with little loss in gain. LAMBETH et al. (1983) found $87 \%$ relative efficiency when they selected for $\mathrm{H}$ at 5 years with a goal of gain in volume at age 20 .

\section{Implications for tree breeding programs}

The inclusion of growth traits in China's loblolly pine breeding program could be beneficial because of its high heritability if growth yields are commercially important. It would be beneficial to select juvenile growth for increasing gains in total volume through the selection of indirect traits because of the strong age-age genetic correlation found for growth traits in China.

Genetic improvement program for loblloly pine in Guangdong province was developed rapidly in the 1990s. In the first cycle of loblolly pine improvement program, we have constructed a nucleus population of 40 elite parents and a main population of 300 parents. The offspring by positive assortative mating and openpollination constituted the second generation base population. At the same time, we introduced a number of families from the United States and considered them as external population. At present we choose superior individuals from top-ranking families; the selected plus trees will form the second-generation breeding population. Based on our results that the most effective years for early selection based on gain per year at half rotation is between age 2 and 5 years for $\mathrm{H}$, and between age 3 and 5 years for DBH, we will select some plus trees by early selection as parental supplement for the breeding population. This will broaden the genetic diversity of breeding population in our program. The plus trees will form a complete second-generation breeding population.

\section{Conclusion}

Conclusions related to using genetic parameters to increase the efficiency of early selection of half rotation- aged growth and form traits in Pinus taeda, based on the analyses of 255 loblolly families planted in China follow:

(1) Significant heritabilities for H, DBH, STR, and CH were observed for combined groups $(0.49,0.31,0.10$ and 0.22 , respectively). Significant heritability was observed for all traits for different groups. Age-trends of heritability estimates for $\mathrm{H}$ and $\mathrm{DBH}$ were non-linear, peaking at age 11 years.

(2) The age-age genetic correlation for $\mathrm{H}$ and $\mathrm{DBH}$ were high with an increased age-age correlation curve, and the correlation reached a very high value (about 0.8 ) at age 5 years for half rotation age (15).

(3) The most effective years for early selection based on gain per year at half rotation is between age 2 and 5 years for $\mathrm{H}$, and between age 3 and 5 years for $\mathrm{DBH}$, and the efficiency was equally efficient as selection at half rotation age. But the highest selection efficiency (the optimal selection age) for $\mathrm{H}$ and $\mathrm{DBH}$ was estimated to be at age 9-11 years for individual (forward) selection. Considering higher heritability of growth trait at early ages, this efficiency has a more practical utility in a breeding program. This indicates that tree breeders don't have to wait for formulation of mature wood (usually around age 15 years) for the selection of breeding material.

\section{Acknowledgements}

The authors thank Y. S. ZENG at Yingde Loblolly Pine Seed Orchard, Yingde City, Guangdong Province for helping us conduct the tests, and Dr. HARRY WU and MiLOs IVKovich of CSIRO Plant Industry, Australia for data analysis, valuable editing and revision on manuscript.

\section{Funding}

This study was financially supported by the Key Projects in the National Science \& Technology Pillar Program (2012BAD01B0203) and Science and Technology Program of Guangdong, China (2011B020302004).

\section{References}

BuRDON, R. D. (1989): Early selection in tree breeding: Principles for applying index selection and inferring input parameters. Canadian Journal of Forest Research 19: 499-504.

DANJON, F. (1994): Heritabilities and genetic correlations for estimated growth curve parameters in maritime pine. Theor Appl Genet 89: 911-921.

ERICSSON, T. and A. Fries (2004): Genetic analysis of fibre size in a full-sib Pinus sylvestris L. progeny test. Scand. J For Res 19: 7-14.

Foster, G. and F. BRIDGWATER (1986): Genetic analysis of fifth-year data from a seventeen-parent partial diallel of loblolly pine. Silv. Gen. 35(2-3): 118-122.

Foster, G. S. (1986): Trends in genetic parameters with stand development and their influence on early selection for volurne growth in loblolly pine. For. Sci. 32: 944-959. 
FrANKLIN, E. (1979): Model relating levels of genetic variance to stand development of four North American conifers. Silv. Gen. 28(5-6): 207-212.

FRIES, A. (2012): Genetic parameters, genetic gain and correlated responses in growth, fibre dimensions and wood density in a Scots pine breeding population. Annals of Forest Science 69: 783-794.

FRIES, A. and T. ERICSSON (2006): Estimating genetic parameters for wood density of Scots pine (Pinus sylvestris L.). Silvae Genet 55: 84-92.

FrIES, A. and T. ERICSSON (2009): Genetic parameters for earlywood and latewood densities and development with increasing age in Scots pine. Ann For Sci 66: 404.

Gilmour, A. R., B. R. Cullis, S. J. Welham, B. J. Gogel and R. THOMPSON (2004): An efficient computing strategy for prediction in mixed linear models. Comput. Stat Data An. 44, 571-586.

Gwaze, D. P. and F. E. Bridgwater (2002): Determining the optimum selection age for diameter and height in Loblolly Pine. Forest genetics 9(2): 159-165.

Gwaze, D. P., F. E. Bridgwater and T. I. Byra (2000): Predicting age-age genetic correlations in tree breeding programs: a case study of Pinus taeda L. Theor. Appl. Genet. 100: 199-206.

Gwaze, D. P., F. E. Bridgwater, T. D. Byram and W. J. LOWE (2001): Genetic parameters estimates for growth and wood density in loblolly pine (Pinus taeda L.). For. Gen. 8: 47-55.

Gwaze, D. P., F. E. BRidgwater and C. G. Williams (2002): Genetic analysis of growth curves for a woody perennial species, Pinus taeda L. Theor Appl Genet 105: 526-531.

Gwaze, D. P., J. A. Woolliams and P. J. Kanowski (1998): Optimum selection age for height in Pinus taeda L. in Zimbabwe. Silvae Genetica 46: 358-365.

Isik, F., B. L. Li, J. Frampton and B. GoldFARB (2004): Efficiency of Seedlings and Rooted Cuttings for Testing and Selection in Pinus taeda. For. Sci. 50(1): 44-53.

KuMAR, S. and J. LEE (2002): age-age correlations and early selection for end-of-rotation wood density in radiate pine. Forest genetics 9(4): 323-330.

LAMBETH, C. C. (1980): Juvenile-mature correlations in pinaceae and implication for early selection. Forest science 26(4): 571-580.

Lambeth, C. C. and L. A. Dill (2001): Prediction models for juvenile-mature correlations for loblolly pine growth traits within between and across test sites. Forest Genetics 8: 101-108.

Lambeth, C. C., J. P. Van BuiJtenen, S. D. Duke and R. B. McCullough (1983): Early selection is effective in 20year-old genetic tests of loblolly pine. Silvae Genetica 32(5-6): 210-215.

LI, L. and H. X. WU (2005): Efficiency of early selection for rotation-aged growth and wood density traits in Pinus radiata. Can. J. For. Res. 35: 2019-2029.

Loo, J. A., C. G. Tauer and J. P. van BuiJtenen (1984): Juvenile-mature relationships and heritability estimates of several traits in loblolly pine (Pinus taeda). Can. J. For. Res. 14: 822-825.

Magnussen, S. (1988): Minimum age-to-age correlations in early selections. Forest Science 34: 928-938.

McKeand, S., T. Mullin, T. Byram and T. White (2003): Deployment of genetically improved loblolly and slash pines in the south. J. For. 101(3): 32-37.

Moran, G. F., J. C. Bell and K. G. EldRIDGe (1998): The genetic structure and the conservation of the five natural-populations of pinus radiate. Can $J$ For Res 18: 506-514.
NANCE, W. L. and O. O. Welles (1981): Estimating volume potential in genetic tests using growth and yield models. In: $16^{\text {th }}$ South. For. Tree Improv. Conf., Blacksburg, VA. 39-46.

NANSON, A. (1969): Juvenile and correlated trait selection. In: IUFRO second meeting working group and quantitative genetics. Sect. proc. 22: 17-25.

NiKLES, D. G. (1966): Progeny tests of slash pine (pinus elliottii engelm.) in Queensland, Australia. Proc. Of the eighth southern conference on forest tree improvement. Silvae Genetica 112-121.

R.2.15.1 (2012): The R Foundation for Statistical Computing, Vienna, Austria.

Shelbourne, C. J. A. (1996): Studies on the inheritance and relationships of bole straightness and compression wood in southern pine. Unpublished PH.D thesis, Department of forest managemet, north Carolina state university at Raleigh, 1-257.

Shelbourne, C. J. A., B. J. Zobel and R. W. Stonecypher (1967): The inheritance of compression wood and its genetic and phenotypic correlations with six other traits in five-years-old loblolly pine. Silvae Genetica 43-47.

Squillace, A. E. and C. R. Gansel (1974): Juvenilemature correlations in slash pine. Forest Science 20 225-229.

Stram, D. O. and J. W. LEE (1994): Variance component testing in the longitudinal mixed effects model. Biometrics 50(4): 1171-1177.

Svensson, J. C., S. E. Mckeand, H. L. Allen and C. AmpBellRg (1999): Genetic Variation in Height and Volume of Loblolly Pine Open-Pollinated Families During Canopy Closure. Silvae Genetica 48: 3-4.

TALBERT, J. T., J. B. JETT and R. L. BRYANT (1983): Inheritance of wood specific gravity in an unimproved loblolly pine population. Silvae Genetica 32: 33-37.

Vogl, C., A. Karhu, G. Moran and O. Savolainen (2002): High resolution analysis of mating systems: breeding in natural populations of pinus radiate. J Evol Biol 15: 433-439.

Williams, C. G. and R. A. MegraW (1994): Juvenilemature relationships for wood density in Pinus taeda. Can. J. For. Res. 24: 714-722.

Williams, C. G. and C. C. LAMBeth (1989): Bole straightness measurement for advanced-generation loblolly pine genetic test. Silvae Genetica 38(5-6): 212-217.

Woessner, R. A. (1965): Growth, form, and disease resistance in four-year-old control- and five-year-old openpollinated progeny of loblolly pine selected for use in seed orchards. North Carolina state school forestry technical report, 28: 1-67.

Wu, H. X., M. B. Powell, J. L. Yang, M. Ivkovic and T. A. MCRAE (2007): Efficiency of early selection for rotationaged wood quality traits in radiate pine. Ann. For. Sci. 64: 1-9.

Xiang, B., B. L. Li and S. McKeAnd (2003): Genetic gain and selection efficiency of Loblolly Pine in three geographic regions. For. Sci. 49(2): 19-208.

Zhong, W. H., B. Q. Cheng and Z. H. HE (1995): Ronguing in Seed Orchard of Loblolly Pine. In: Shen Xihuan ed. Forest Tree Improvement in the Asia-pacific Region[M]. Beijing: China Forestry Publishing House, 208-216.

ZoBEL, B. (1961): Inheritance of wood properties in conifers. Silvae Genetica 10(3): 65-70.

ZoBel, B. and J. P. vAN BuIJTENEN (1989): Wood variation: its causes and control. Springer-Verlag, New York. 